\title{
TIDAL: UMA ANÁLISE DOS VALORES PERCEBIDOS PELOS USUÁRIOS DE MÚSICA POR STREAMING
}

\author{
Alda Rosana Duarte de Almeida \\ Professora da Universidade Federal do Rio de Janeiro (UFRJ), Escola de Comunicação e do \\ Programa de Pós-Graduação em Tecnologias e Linguagens da Comunicação - PPGTLCOM. \\ Doutora em Ciências pela USP (2010) e mestre em Administração pela FGV (2005). \\ alda.almeida@eco.ufrj.br \\ Gabriela Oliveira da Silva \\ Bacharel em Publicidade e Propaganda pela Escola de Comunicação da Universidade Federal \\ do Rio de Janeiro. \\ olv.gabriela@gmail.com
}

\begin{abstract}
Resumo
A música faz parte da vida de boa parte dos indivíduos, seja como forma de expressão, manifestação social ou entretenimento, e na última década pudemos observar importantes mudanças na forma de consumi-la. Atualmente, os serviços de música por streaming dominam o setor de distribuição de música digital, sendo responsáveis por mais da metade da receita de música em diversos países, incluindo o Brasil. Nesse cenário, encontra-se o TIDAL, serviço de streaming com conteúdo exclusivos e som de alta fidelidade, ele briga com concorrentes de peso a fim de conquistar público e aproximar artistas e fãs. Assim, nesse artigo buscou-se analisar a percepção de valor por parte dos seus consumidores, de acordo com as propostas da plataforma. Através de uma análise observacional e das entrevistas em profundidade, obteve-se resultados que mostram que o valor do serviço está diretamente relacionado aos conteúdos exclusivos disponíveis, revelando que o áudio de maior qualidade não influencia na decisão final dos consumidores. Desta maneira, infere-se que, apesar dos diferenciais oferecidos, falta ao TIDAL benefícios claros e um direcionamento para relacionamento de longo prazo, incrementando seu valor de marca em relação aos concorrentes.
\end{abstract}

Palavras-chave: Música Digital. Conteúdos Digitais. Tidal. Streaming. Entretenimento Digital.

\section{TIDAL: AN ANALYSIS OF THE USERS`PERCEIVED VALUE OF MUSIC} STREAMING SERVICES

\begin{abstract}
Music is a huge part of most people's lives, whether as a form of expression, social manifestation or entertainment, and in the last decade we were able to observe important changes in the way we experience it. Nowadays, the music streaming services rule the distribution sector of digital music, being responsible for more than half of music revenue in many countries, including Brazil. In this scenario there is TIDAL, a new streaming service with exclusive content and high definition sound, which fights with major competitors to reach the public and bring artists and fans closer. In light of that, the costumers' perception of value was reviewed, according to the platform's proposal. The results obtained through observatorial analysis and in depth interview research showed that the service value is directly related to the exclusive contents available, revealing that the sound quality does not influence the consumers' final decision. Due to this, it is possible to conclude that, despite the differentials
\end{abstract}


currently offered, TIDAL lacks clear benefits and a long-term strategic planning to build a relationship that will differentiate it from its competitors.

Keyword. Digital Music. Digital Content. Tidal Brazil. Streaming. Digital Entertainment.

\section{INTRODUÇÃO}

A música tem sido parte importante da cultura do ser humano desde a era pré-histórica, uma vez que alguns estudiosos acreditam que a música surgiu entre 30 mil e 60 mil anos atrás (ALBRIGHT, 2015). Através dos séculos ela tem exercido o papel de produto social e simbólico em diferentes formações culturais, criando vínculo afetivo entre indivíduos (SANTINI, 2006), funcionando como expressão cultural das mais diversas sociedades. Essa sua adaptabilidade nos variados períodos históricos e tecnológicos mostra a força e relevância desse produto cultural.

A partir do início do século XXI vemos surgir, decorrente do cruzamento de tecnologias digitais com a música, novas tendências de negócios. Acompanhando as transformações vem os desafios enfrentados pela indústria fonográfica, desde então. Se no tocante à gravação e produção da música a indústria ganha em facilidade e barateamento, no que diz respeito à distribuição encontram-se dificuldades como a pirataria. Como explicitado por Kischinhevsky e Herschmann (2011, p. 1) é um fato que nunca a música esteve tão acessível, mas que jamais foi tão difícil estabelecer o seu valor de troca, num mercado de bens simbólicos, hoje caracterizado pela superoferta de commodities culturais. Por conta disso, ocorre um embate entre a facilidade de obter músicas e álbuns de forma gratuita, ainda que ilegal, através da internet, e o valor atribuído às produções pela indústria, que considera na soma o custo de produção, divulgação e distribuição; e o trabalho de técnicos, músicos e intérpretes. Não obstante, o compartilhamento livre de arquivos digitais ocorre à margem dos direitos dos artistas e das gravadoras, acarretando queda na venda de CDs e baixa nas receitas de música.

Surgiu então, a necessidade de desenvolver um ambiente de aquisição de música digital que não violasse os direitos autorais dos artistas. A solução encontrada estava na compra e venda dos arquivos digitais, isso é, a venda legal de músicas (FERNANDES et. al, 2012, p. 26 apud RIBEIRO, 2016, p. 30). Como resposta ao comportamento de download ilegal, começam a surgir alternativas para a comercialização autorizada de cópias digitais na internet no início dos anos 2000, como a iTunes Store (loja da Apple que permite adquirir faixas isoladas). Do mesmo modo vemos o aparecimento de plataformas de streaming de música, nas quais o 
conteúdo é reproduzido na medida em que o usuário recebe, não havendo armazenamento do mesmo. De acordo com Wachowicz e Virtuoso (2018, p.5) esse serviço “é uma tecnologia que realiza uma distribuição online de pacotes de dados" que permite uma maior interatividade para o usuário, deixando a música mais acessível para o consumidor.

Desde a chegada das plataformas de streaming no Brasil em 2011 (COM STREAMING, 2017) vemos um crescimento considerável na receita obtida com música digital. No país, o aumento foi de aproximadamente 52\% (cinquenta e dois por cento) de 2015 para 2016 de acordo com o relatório anual publicado pela Federação Internacional da Indústria Fonográfica (IFPI em inglês), passando a ser o principal modelo de distribuição de música do setor fonográfico. A proporção do consumo de música no Brasil em 2017 é de aproximadamente $23 \%$ (vinte e três por cento) para o físico e $77 \%$ (setenta e sete por cento) para o digital (STREAMING, 2017). Assim, o mercado de música digital por streaming vem para conciliar a demanda da indústria musical em manter seus ganhos e aquecer o mercado garantindo seus direitos autorais, mantendo a necessidade de um serviço que seja de fácil acesso e baixo custo para o consumidor.

É neste cenário que o presente artigo se insere. O TIDAL, objeto desse estudo, chega ao mercado em 2015, trazendo consigo como diferencial para os seus assinantes a "qualidade do áudio" de alta fidelidade e "conteúdos exclusivos" (ROCHA, 2015) enquanto oferece um

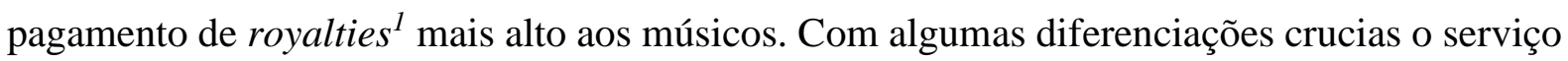
vem para bater de frente com o Spotify, maior plataforma de streaming e principal alvo de críticas por parte dos artistas, que consideram seu modelo uma desvalorização da indústria ao oferecer plano de acesso gratuito. Diferente de seu concorrente, o TIDAL possui dois modelos de assinatura e ambos cobram pelo acesso, proporcionando o maior índice de pagamento de royalties aos artistas (QUAL SERVIÇO, 2017).

A distribuição dos royalties dos direitos autorais e conexos é realizada pelos serviços
de streaming de forma proporcional entre as músicas acessadas em determinado
território e período de tempo, o que significa que os artistas que têm mais acessos
(streams) ganham a maior parte dessa distribuição dos lucros, enquanto os que tocam
menos ganham a menor parte (TARAN, 2015 apud KISCHINHEVSKY et al. 2015,
P. 307).

A disputa por royalties fez com que o Spotify perdesse grandes artistas como Beyoncé, que lançou com exclusividade seu último álbum no TIDAL, empreendimento de seu marido, o

\footnotetext{
${ }^{1}$ Royalties são os valores pagos em decorrência de um o direito de receber um percentual do lucro sobre as vendas ou exploração de um produto ou serviço.
} 
rapper Jay-Z. Este conflito revela um ponto sensível na indústria, que briga por uma melhor remuneração enquanto busca alternativas que eliminem a pirataria do mercado. Da parte dos artistas, o valor de royalties por reprodução é insatisfatório e gera polêmica; entretanto o número de adeptos aos serviços de streaming não para de crescer (CARVALHO, 2017), o que indica o sucesso do modelo de negócio. Como apontado por Kischinhevsky et al. (2015) as plataformas de streaming têm conseguido oferecer uma experiência de consumo que agrada os usuários, independente da polêmica, o que se confirma no crescimento do uso desses serviços.

Assim, a motivação deste trabalho foi despertada pelo nascimento deste novo serviço, que destoa da proposta das demais plataformas já existentes. Consequentemente tem-se como objetivo analisar a percepção de valor do TIDAL por parte dos consumidores/usuários, de acordo com sua proposta de som de alta qualidade, conteúdo exclusivo e poder aos artistas. A fim de atingir o objetivo principal foi necessário alcançar alguns objetivos específicos tais como analisar a eficiência das estratégias empregadas na divulgação e venda do serviço e o quanto e como elas afetam na decisão de assinatura do serviço e influência na formação da imagem da marca diante do público. Além disso, da bibliografia existente sobre o tema, poucos trabalhos abordam a questão que envolve a polêmica dos royalties de forma a considerarem a opinião do consumidor final no processo.

\section{O MERCADO DE MÚSICA DIGITAL}

Apesar do longo histórico sobre a música, aqui o ponto de partida será o surgimento da música digital, como tecnologia e mercadoria, dentro do contexto da cultura de massas, enquanto elemento propagador da música. E embora a produção digital de música venha ocorrendo desde os anos 1960 foi apenas no início década de 80 que os primeiros discos compactos começaram a ser comercializados (ALBRIGHT, 2015). Desde então a forma de consumir música passou por mudanças radicais, especialmente nos últimos 30 anos, com os progressos da reprodutibilidade técnica. Esse primeiro grande formato digital, dominou mercado ao longo dos anos 90 até o início dos anos 2000 (ALBRIGHT, 2015). Com o êxito do $\mathrm{CD}$, o consumo de música se tornou individual e semi personalizado, através de meios como o Discman, com seus fones de ouvido, levando o som diretamente ao canal auditivo, encapsulando o ouvinte em um ambiente sonoro personalizado se dá um primeiro passo em direção ao consumo móvel e individual. Assim, o consumidor passa a ouvir música em 
"qualquer lugar e a qualquer momento", o que "faz com que ouvir música seja um comportamento emblemático do contemporâneo" (CASTRO, 2005, p.30).

Com a disseminação da World Wide Web e a expansão dos serviços comerciais, a Internet chega como um prenúncio das possibilidades de um futuro interativo e globalizado. A ameaça causada pela difusão do MP3 foi o primeiro grande desafio que a indústria da música enfrentou (CARVALHO, 2006). Devido ao crescimento da distribuição da banda larga e a criação de serviços de música online, como o Napster, primeiro software para compartilhamento de música baseado em sistema $\mathrm{P}_{2} \mathrm{P}^{2}$, a forma como a música é acessada e consumida sofre grandes alterações (MARTINS; SLONGO, 2014). Segundo Lima e Santini (2009), é dentro da cibercultura, conceito desenvolvido por Pierre Lévy, que música em sua forma digital ganha potencial de obra aberta, que o consumidor adquire a competência de produtor e intermediário, com a capacidade de copiar e compartilhar arquivos com facilidade, de forma barata e sem que haja perda de qualidade.

Albright (2015), destaca a pirataria como uma das consequências da emergência do MP3: com a possibilidade de arquivos menores e compartilháveis através da tecnologia P2P. Em decorrência disso o download ilegal se tornou prática comum entre os usuários de internet que, mesmo com os esforços das grandes empresas do setor, não foi possível deter. É a partir deste cenário que vemos surgir uma alternativa de negócio que satisfaça, ainda que minimamente, indústria e consumidores: o streaming. Ele nasce como uma possibilidade de consumo de arquivos em nuvem, sem que seja necessário qualquer tipo de armazenamento físico do áudio, o que implica diretamente em uma nova forma de distribuição de conteúdo e no surgimento de novos intermediários no processo comercial de música digital.

Segundo Francisco e Valente (2016), streaming é uma tecnologia de transmissão online de dados, seja em áudio e/ou vídeo, em tempo real, sem que haja a necessidade de armazenamento, podendo ter duas modalidades: não interativo (modelo que se aproxima das rádios tradicionais) e o interativo ou on demand. O TIDAL se encaixa no modelo de streaming interativo, oferecendo ao consumidor um serviço de música digital que o permita ouvir suas músicas preferidas a qualquer momento e em qualquer lugar, através do seu smartphone, na ordem em que preferir.

\footnotetext{
${ }^{2}$ Peer-to-peer, que significa par-a-par, é uma arquitetura de redes de computadores onde cada um dos pontos ou nós da rede funciona tanto como cliente quanto como servidor, permitindo compartilhamentos de serviços e dados sem a necessidade de um servidor central (BENCHER, 2006)
} 
Devido à adesão do mercado ao streaming e seu sucesso entre os consumidores vemos a receita de vendas de música digital superar as vendas físicas pela primeira vez em 2015 (GLOBAL, 2016), o que reflete a adaptação da indústria ao novo formato de consumo de música e de negócio. É interessante observar também que o mercado global de música, depois de perder aproximadamente 40\% (quarenta por cento) de sua receita nos últimos 15 anos, cresceu pelo segundo ano consecutivo, impulsionado por $60 \%$ (sessenta por cento) do faturamento com serviços de músicas pela internet (FERRARI, 2015).

Como observado por Herschmann (2010) o crescente emprego das novas tecnologias e das redes sociais na web como forma de reorganização do mercado funciona como estratégia de comunicação e circulação de conteúdo, além de formação e renovação de público. A mudança nos formatos anda de mãos dadas com a mudança do comportamento do consumidor em relação aos produtos fonográficos. Mas esse consumidor continua cada vez mais exigente com os serviços prestados, demandando relacionamento de qualidade e duradouro com as empresas (BARRETO, 2015; KOTLER; KELLER, 2006). O cerne da questão ainda reside em como os atores da cadeia produtiva da indústria da música lidarão com tais mudanças.

\subsection{Música digital no Brasil}

O Brasil tem sido um dos mercados mais movimentados e lucrativos para a indústria da música desde a década de 1960, graças a fatores como o desenvolvimento de televisão comercial: o surgimento de uma nova geração de compositores e intérpretes dentro dos movimentos culturais emergentes tais como a Bossa Nova, MPB, jovem-guarda e tropicália; e a transformação da juventude brasileira em público-alvo da indústria de discos (DE MARCHI et al., 2011). Mas nos últimos anos o mercado de música nacional se mostrou inquieto, sendo possível observar a oscilação entre as receitas venda física e venda digital.

\footnotetext{
O crescimento do mercado digital no Brasil tem sido tão expressivo nos últimos anos que, em 2014, uma seção do relatório global da IFPI foi dedicada ao país aproximadamente $30 \%$ (trinta por cento) em relação ao ano anterior. Esse crescimento foi responsável por fazer com que, mesmo diante de uma queda de cerca de $15 \%$ (quinze por cento) nas receitas com vendas físicas, o mercado fonográfico brasileiro total crescesse $2 \%$ (dois por cento) passando a corresponder a $\mathrm{R} \$ 581,7$ milhões (FRANCISCO; VALENTE. 2016, p. 270).
}

Desde o início do processo de digitalização da indústria fonográfica, as indústrias culturais têm enfrentado sérios problemas para conciliar as novas práticas de distribuição e consumo de fonogramas com a tradicional estrutura de comercialização da música gravada (DE 
MARCHI et al., 2011). Segundo os autores, o espaço que antes as grandes gravadoras dominavam agora era dividido com outras nacionais e independentes. Além disso, como nos principais mercados de música ao redor do planeta, era preciso lidar com intermediários um tanto indesejáveis, por conta do crescimento do mercado de reproduções "piratas". Entre os anos de 2000 e 2009, verificava-se uma diminuição de aproximadamente $73 \%$ (setenta e três por cento) na venda de discos físicos, impactada principalmente pelo surgimento de novas formas de distribuição e consumo de arquivos musicais digitalizados. Entre eles o compartilhamento $P 2 P$, seja pela internet ou telefones celulares, sendo este último uma peculiaridade do mercado brasileiro.

Ao mesmo tempo em que as vendas físicas entram em declínio verificamos que as vendas digitais continuaram a apresentar elevação na casa dos dois dígitos, tendo crescido $23 \%$ (vinte e três por cento) em 2016, comparado ao ano anterior. De acordo com a IFPI (GLOBAL, 2016), o mercado brasileiro de fonogramas digitais é um dos mais lucrativos da América Latina (junto ao mexicano e ao argentino), representando 86\% (oitenta e seis por cento) do mercado digital de música nesse continente, principalmente impulsionado pelo streaming, estimulado pelo mercado de telefonia móvel (FRANCISCO; VALENTE, 2016).

Determinante para o crescimento do mercado de música digital no Brasil, assim como em praticamente todo o mundo, o segmento de streaming interativo cresceu aproximadamente $52 \%$ (cinquenta e dois por cento). De forma geral, as plataformas de música digital podem ser vistas como espaços virtuais ou redes sociais musicais online, onde o objetivo central é a divulgação, compartilhamento e consumo musical (SILVA, 2016).

\subsection{Pirataria e serviços de música por streaming}

Quando o MP3 começa a despontar como principal formato de música digital os gigantes da indústria fonográfica não estavam preparados para as consequências que se seguiriam. Segundo Santini (2006, p. 79) o caráter aberto do formato implicava em duas coisas: qualquer um podia criar programas ou aparelhos para tocar MP3, e os arquivos podiam ser copiados livre e infinitamente, sem qualquer dificuldade. Diversas plataformas baseadas na tecnologia P2P surgiram, possibilitando a troca de arquivos na internet de forma gratuita, como o KaZaA em 2001 (KLEINA, 2011) e eMule em 2002 (ALVES, 2015). "A praticidade desta forma de colecionar música seria o principal atrativo (...). O hábito de compartilhar arquivos de música online está em consonância com os ideais libertários que preconizam a internet como 
um ambiente de trocas e colaboração" (CASTRO, 2005, p. 31). É curioso perceber, como apontou Bandeira (2005), que, no ano de 1999, quando o Napster começava a funcionar, a indústria fonográfica registrou o último período de ascensão nas vendas mundiais de discos. Ao relacionar o fenômeno de downloads de músicas com a suposta crise do mercado cria-se o estigma da pirataria. Estes números serviram de munição à indústria fonográfica para reiterar o discurso contra a pirataria, isto é, a cópia ilegal de CDs e as trocas de arquivos pela Internet com músicas protegidas por direito autoral (BANDEIRA, 2005, p.8). Não demorou muito para que as gravadoras reagissem e acionassem a justiça contra tais plataformas, a fim de impedir o download de música ilegal. Apesar dos esforços, medidas coercitivas não foram suficientes para impedir os compartilhamentos de música. Martins e Slongo (2014, p.640) pontuam que “a diversificação de plataformas de entrega e o compartilhamento podem ter aumentado o tempo de audição de música, mas o download não autorizado de conteúdo protegido através da Internet tem levantado preocupações para o mercado fonográfico mundial”.

É nesse contexto, visando amenizar a queda nas vendas, e o desinteresse em se comprar música, que se situa o impasse entre artistas, gravadoras e serviços de streaming. É importante lembrar que, historicamente as tendências do mercado são ditadas pelas gravadoras, moldando o formato das vendas e direcionando os esforços de publicidade. $\mathrm{O}$ embate desses atores do mercado se torna mais efetivo após as inovações tecnológicas que acarretam desafios econômicos. Kischinhevsky et al. (2015) chamam as tensões resultantes da reconfiguração da indústria fonográfica através do mercado de música digital de “destruição criadora”. De acordo com Castro (2006) a entrada em cena das tecnologias digitais tornou complexa ainda mais a relação entre autores e receptores, problematizando o papel das instâncias intermediárias e trazendo sérias consequências para a implementação dos direitos autorais. O desafio é conciliar as novas práticas de consumo de conteúdos digitais aos interesses dos agentes da indústria da música (KISCHINHEVSKY et al., 2015). Este processo tem como ator principal o modelo de streaming.

Os serviços de músicas por streaming, que cobram pela escuta a partir do consumo de dados, surgiram no começo de 2010 com o processo de convergência midiática mais influente e popular, principalmente com a ascensão de dispositivos móveis (SILVA JR, 2016, p. 6). Um dos primeiros serviços do tipo a chegar ao Brasil foi o Rdio em 2011, que encerrou suas atividades 2015 após declarar falência. Apesar de pioneiro, ele encontrou grande dificuldade para competir com outros serviços de música, como Deezer e Spotify, que desembarcaram no país em 2012 e 2014 respectivamente, seguidos pelo Apple Music e TIDAL em 2015. Como 
resultado da multiplicação de players no mercado pudemos observar a superação da renda de música física pela digital no ano de 2016 (COM STREAMING, 2017).

Serviços como Spotify, principal concorrente do TIDAL, baseados em assinaturas, ajudaram na recuperação da indústria, enquanto o mercado de formato físico continuou a encolher, junto com o faturamento de downloads (SMOUT, 2017). Mas, apesar dos dados favoráveis, existem duas facetas principais a serem tratadas no que diz respeito à atuação desses serviços de streaming. Se por um lado ele atua como uma alternativa ao consumo de música digital por meio de download, ou ilegal; por outro os valores repassados para as gravadoras e artistas são considerados pequenos, o que resulta numa certa resistência por parte de alguns artistas em relação ao modelo (TAPIA, 2015).

\section{O TIDAL: STREAMING DE ALTA DE QUALIDADE}

O TIDAL tem seu nascimento em 2015, após a compra da empresa sueca de serviços móveis sob o nome de Aspiro pela Project Panther, empresa que tem como dono o rapper americano Jay Z. É neste ano em que o mercado vê renascer a plataforma ao ser transmutada em um modelo de negócio diferente do inicial, ressurgindo como um novo serviço de música por streaming. Ele chegou no mercado com uma proposta idealista que tratava do respeito aos artistas e preservação da música.

Em seu site oficial, o TIDAL declara que ao empoderar os artistas com o controle criativo e ao permiti-los atuar como artista-dono da empresa, se posicionando como criador de valor para os fãs e promovendo uma relação mais forte entre artista-fãs, proporcionando uma experiência melhor e possibilitando aos músicos/cantores compartilhar o que eles querem, quando e como quiserem, direto aos fãs. Seja através de músicas exclusivas e vídeos exclusivos, ou experiências ao vivo, o TIDAL fornece algo único (TIDAL, 2018).

Com a promessa de revolucionar o mercado e bater de frente com seus principais concorrentes, começou com um catálogo de aproximadamente 35 (trinta e cinco) milhões de músicas e pelo menos 32 (trinta e dois) álbuns exclusivos de artistas como Prince, Beyoncé e o próprio Jay Z, disponível em mais de 52 países. Em 2016 o serviço contava com mais de 42 milhões (quarenta e dois) de músicas em seu catálogo e 140.000 vídeos de alta qualidade (TIDAL, 2016a), além de disponibilizar transmissões de evento ao vivo e proporcionar uma experiência única ao distribuir ingressos para shows de diversos artistas (TIDAL, 2016b). Outra característica dele é sua qualidade de áudio, sendo duas opções disponíveis com preços 
diferentes: a comum, similar aos outros serviços de streaming e a segunda em alta definição utilizando a tecnologia LossLess que promete qualidade de $\mathrm{CD}$, que é oferecido no plano TIDAL HiFi, baseado no FLAC, um formato de transmissão mais robusto e realista. Este formato atende um perfil diferente de uso e consumo, e destina-se a quem exige máxima qualidade, abrindo mão do espaço, já que os arquivos tendem a ser grandes (GARRET, 2017).

O TIDAL também oferece conteúdos e experiências únicas, por meio da assinatura o usuário obtém singles, álbuns e vídeos, acesso a ingressos e experiências desenvolvidas exclusivamente para seus membros. Ele tem por proposta ser o intermediário perfeito: estar ao lado dos artistas na questão de pagamento de royalties e oferecer aos seus assinantes conteúdos diferenciados como álbuns exclusivos, transmissão ao vivo de eventos e playlists com curadoria dos próprios artistas. Destaca-se a postura de seus artistas-donos que acreditam na criação de um modelo mais sustentável para a indústria fonográfica.

A questão do pagamento de royalties pelos serviços de streaming tem sido tema constante de debate no setor. Por conta do baixo valor pago por serviços como Spotify e Deezer e de seus modelos de assinatura freemium, diversos artistas se posicionaram contra eles. A grande personagem na queda de braço com os serviços de streaming, Taylor Swift, estendeu seu boicote ao Spotify por três anos. A discussão girava em torno da modalidade gratuita, e o CEO do Spotify, Daniel Ek, que defendia a prática de tornar toda a biblioteca da empresa disponível em uma modalidade gratuita apoiada em publicidade, enquanto Swift demandava que sua música estivesse disponível apenas para os usuários pagantes, gerando mais receitas para os artistas. O embate só teve fim quando o Spotify alterou sua política em abril de 2017 permitindo que os artistas restringissem os novos lançamentos aos clientes pagantes (SHAW, 2017). No entanto, o catálogo de músicas de Taylor Swift já fazia parte da biblioteca do TIDAL durante esse tempo, uma vez que serviço não oferece plano "gratuito" em seus pacotes, apenas um trial de um mês.

O TIDAL também se propõe a conectar os artistas diretamente aos fãs, dando-lhes uma plataforma para se envolver, incluindo shows ao vivo exclusivos, eventos, encontros com artistas e concertos para que os membros desfrutem. Entre as estratégias adotadas pelo serviço para conseguir se conectar com esta nova geração está o lançamento de documentários e conteúdos de bastidores, além de apoiar eventos filantrópicos de seus artistas e oferece shows beneficentes como o TIDAL X. Outro diferencial é segmentar através de dados geográficos da plataforma e interações com fãs as experiências oferecidas, de forma que cada público usufrua o conteúdo de sua preferência. A transmissão ao vivo do show de desfile Fenty by Rihanna em 
Paris, e a distribuição de convites para a segunda edição do show de caridade organizado por Jay Z e Beyoncé, são bons exemplos (HAVENS, 2016). É importante ressaltar que tais ações fazem parte do posicionamento pretendido pelo TIDAL: um serviço de exclusividades e promoção da música como arte.

Apesar dos diferenciais oferecidos, quando o TIDAL chegou ao mercado brasileiro em 2015, encontrou alguns concorrentes já estabelecidos, com os quais precisa disputar espaço e a confiança dos consumidores. Porém, nota-se que tanto o modelo de negócio quanto as funcionalidades são similares.

O concorrente mais famoso e mais querido é o Spotify - Música para todos - sendo o maior dos serviços de streaming no mercado. Os grandes diferenciais do Spotify em relação aos concorrentes dizem respeito à compatibilidade e às funcionalidades, uma vez que roda em uma grande gama de aparelhos - que vão de celulares e TVs até em aparelhos de som de carros (JORDÃO, 2016). Além de tudo, tem um apelo de rede social, que falta nos outros serviços, pois é muito comum que amigos acompanhem o que os outros estão ouvindo, que compartilhem novidades e dividam playlists, funcionando como um experimento social a partir da perspectiva musical. Já o Deezer - Onde a música vive - nasceu como um site de compartilhamento de músicas. Ao longo dos anos, sofreu altos e baixos em sua base de usuários por conta de problemas com direitos autorais (JORDÃO, 2016), mas é hoje a plataforma de streaming que apresenta a maior biblioteca musical, com acervo mais democrático que vai do gospel nacional até o reggaeton de Porto Rico, passando pelo hip-hop holandês (SASSARD, 2017).

O terceiro concorrente mais importante a ser destacado é a Apple Music - Escute aqui o sucesso que vem aí - que começou no mercado da música de forma tardia - em meados de 2015 - , mas com força suficiente para abalar os concorrentes. Ele é alimentado pela vasta biblioteca musical diversificada que existe no programa iTunes (RIBEIRO, 2016) e uma rádio exclusiva (a Beats 1, gratuita para qualquer usuário), tendo ganho adeptos rapidamente. Parte do sucesso, obviamente, se deve à enorme quantidade de consumidores dos produtos da Apple. Uma grande vantagem é poder combinar a biblioteca do Apple Music com suas músicas antigas do iTunes, já que esse serviço permite enviar até 100 mil músicas para o iCloud (JORDÃO, 2016).

Enquanto TIDAL e Apple Music trabalham em cima de conteúdos exclusivos, como filmes de bastidores e lançamentos prévios, Spotify e Deezer, em contraposição, prezam pela democratização dos conteúdos. As diferenças não param por aí. Dos quatro, apenas o Spotify 
e Deezer oferecem uma versão gratuita, e somente o TIDAL oferece duas opções de qualidade de áudio. No Brasil, o TIDAL, que é exclusivamente pago, sendo possível experimentar gratuitamente o serviço por 30 dias, tem uma versão premium, de qualidade comum, e o TIDAL $\mathrm{HiFi}$, que oferece uma qualidade do áudio superior, uma vez que as músicas são em Lossless. Este é um dos principais argumentos de venda usados pelo TIDAL, seus áudios tocam a 1411 kbps enquanto os do Spotify, por exemplo, não passam de 320 kbps (ROCHA, 2015). Não há outro serviço no mercado que ofereça qualidade igual ou parecida, estando à frente de seus concorrentes. Ainda assim, ele teria como público-alvo os audiófilos, aqueles que prezam pela alta qualidade de som, e demandaria o uso de fones de ouvido ou equipamento de som que permita aproveitar a qualidade das músicas, uma vez que os acessórios comuns não dariam conta de processar todas as camadas de som disponíveis. O ponto fraco dessa abordagem é que o usuário médio parece estar satisfeito com a qualidade do áudio padrão no mercado.

Todavia, mesmo com o apoio de alguns dos maiores artistas da atualidade, o TIDAL conseguiu vingar. Nos primeiros meses o sucesso se apoiou no fator novidade e muitos usuários usavam o mês grátis para experimentar, mas não passavam disso. Em 2016 o Wall Street Journal reportou uma perda de 28 milhões de dólares em 2015, o dobro do ano anterior à aquisição de Jay Z (McALONE, 2016). No mesmo ano o jornal norueguês Dagens Næringsliv noticiou uma série de dívidas dele com diversas empresas, incluindo desde companhias de táxi até bancos (COOK, 2016). O TIDAL também sofreu com acusações de seus artistas parceiros, como Kanye West, amigo pessoal do rapper Jay Z, que alegou não ter recebido o valor combinado de royalties. O seu último álbum, "The life of Pablo", foi exclusivo do TIDAL por cerca de um mês e meio após seu lançamento, no início de 2016, o artista alegou ter gerado cerca de um milhão e meio de novas assinaturas para o serviço, fato esse que o daria direito a um bônus, que não teria sido pago (KANYE, 2017). Como consequência da disputa entre artista e empresa, West abandonou a parceria em 2017. Entre as polêmicas que permeiam a história do TIDAL está a acusação de maquiar os números de assinaturas, informando possuir mais assinantes do que o real (GREENBURG, 2017).

De todos os fatores apresentados aqui é possível observar que a escolha em priorizar os interesses dos artistas, que tem direcionado o negócio, se mostrou falha, uma vez que quem sustenta os serviços de streaming são os usuários pagantes e anunciantes. 


\section{MÉTODO E ANÁLISE DE RESULTADOS}

A presente pesquisa se baseia em um estudo de caso, com objetivo de auxiliar na compreensão de fenômenos sociais complexos (YIN, 2001), colaborando com compreensão dos fenômenos individuais, organizacionais, sociais e econômicos que envolvem o TIDAL, a fim de analisarmos a eficiência das estratégias empregadas na divulgação e venda do serviço e o quanto e como elas afetam na decisão de assinatura do serviço e influência na formação da imagem da marca diante do público. Para tal, foram realizadas pesquisas qualitativas, com abordagem exploratória, que são baseadas em pequenas amostras, não-estruturadas e proporcionam esclarecimentos sobre o contexto do problema (MALHOTRA, 2001). As pesquisas foram divididas em: uma análise observacional dos comentários sobre o serviço no Twitter e as resenhas críticas feitas na loja de aplicativos do Google, a Play Store, a fim de capturar as opiniões espontâneas sobre o TIDAL, e entrevistas em profundidade com assinantes e ex assinantes da plataforma.

No Twitter foram analisados cerca de trezentos e cinquenta tweets compreendendo o período de lançamento do TIDAL em 2015 até 10 de novembro de 2017, enquanto na Play Store foram avaliadas mais de trinta resenhas feitas pelos usuários. O método de pesquisa na rede social foi baseado na busca por uma combinação de palavras-chaves relacionadas ao tema, tais como "tidal pirataria", "tidal spotify", "tidal exclusividade", "tidal problema", "tidal gostei”. Através desta análise observacional foi possível identificar as principais críticas à plataforma e seu modelo de negócio, e o sentimento gerado pelo serviço no que diz respeito à sua qualidade e funcionamento.

As entrevistas em profundidade se deram por uma amostra por conveniência, onde a escolha dos entrevistados se baseou em dois requisitos principais: já ter utilizado a plataforma por pelo menos um mês ou ser assinante ativo do serviço. Foram entrevistados oito indivíduos no total, sendo quatro assinantes e quatro ex assinantes do TIDAL, com idades entre 17 e 26 anos. Para melhor identificação, os entrevistados foram codificados pela letra "E" sendo que E1, E2, E6 e E7 são do sexo masculino; e de E1 até E4 assinantes. As entrevistas foram realizadas através do WhatsApp, serviço de troca de mensagens instantâneas, seja por meio de chamada de voz ou troca de áudio, e ocorreram entre os dias 03 de outubro e 03 de novembro de 2017.

Dos trezentos e cinquenta tweets analisados foram selecionados sessenta ao todo, sendo que a seleção foi feita de acordo com o nível de informação exposta e com a pertinência em 
relação ao objetivo da pesquisa. O mesmo critério foi utilizado na seleção de vinte e uma resenhas críticas feitas na Play Store. Os comentários sobre a plataforma foram categorizados em dois grupos: Funcionalidades, no que diz respeito ao desempenho do serviço, sua interface, qualidade de som, e demais atributos; e Conteúdo, em relação aos artistas exclusivos do TIDAL e sua biblioteca de músicas de uma forma geral. A análise das entrevistas foi realizada em conjunto, complementando o que foi diagnosticado na observacional.

No que diz respeito à interface (layout e design), o TIDAL divide opiniões. Apesar de visual similar com outros concorrentes, a plataforma ainda recebe duras críticas no que diz respeito à usabilidade e organização de seu acervo. Ao deixar sua resenha na Play Store, um usuário comenta:

\begin{abstract}
Qualidade do aplicativo é incomparável, mas incomoda o design desorganizado (como aquilo de as músicas offline estarem em um lugar específico, é você ter que favoritar o álbum e todos os artistas se quiser que apareçam nas duas listas). Como sugestão, acharia interessante ter um espaço apenas de rádios de estilos específico (como o "estilos e momentos" do spotify) e playlists de jogos. Excetuando essas duas coisas, o app, é mais que recomendado pra quem busca a melhor qualidade de áudio. O App, também não apresentou bugs [...].
\end{abstract}

Durante a análise identificamos usuários do Twitter que tiveram experiências frustrantes com a navegação na plataforma: “@Igor8Ramos Eu tô odiando o TIDAL, muito ruim de achar as coisas, mt bagunçado... Prefiro Spotify” assim como “@LilyJonas13 As playlists do tidal são horríveis eu prefiro mil vzs do Spotify". Quando consideramos os atributos citados acima, o desempenho do TIDAL deixa a desejar. A performance de um serviço online tende a ser medida com base em sua facilidade de uso e atratividade física. Rapidez, navegabilidade e comunicação clara são algumas das características que contribuem para a avaliação de uma plataforma e fazem falta no serviço. Mas, apesar dos problemas mencionados anteriormente, a E4 considera "fácil e tranquilo de usar", e se diz satisfeita com a experiência proporcionada quando questionada sobre sua relação com a plataforma/app. Já E3 considera o design simples, mas diz sentir falta da personalização do conteúdo:

Eu gosto muito dela, só que eu acho ela simples, sabe? Tem tudo lá... os estilos, Hip-
Hop, Rock, R\&B e tem também a área de novidades, que fica logo na página inicial,
que tem todos os singles que tão lançando agora, independente do artista que seja. A
única coisa que eu sinto falta é da personalização do conteúdo, entendeu? Porque, por
exemplo, no Spotify a gente tem as descobertas da semana e essas coisas e no TIDAL
não existe isso, a coisa é bem padrão. Não importa o que você tem escutado, qual o
seu estilo, eles não usam esses dados pra personalizar sua experiência. Mas no geral
é uma plataforma bem simples e intuitiva, e eu não tenho problema pra usar não. (E3)

Dos comentários observados na rede social, alguns transparecem o apreço pela alta qualidade do som, elegendo-a como o principal diferencial do serviço, normalmente após 
compará-la com algum outro. Tendo como evidência os comentários de: “@gomesgabrel só uso TIDAL pq FLAC é uma qualidade de áudio absurda”; “@lordegod As músicas do spotify online são só $124 \mathrm{kbps}$ prefiro as do TIDAL chegam a 326kbps”. Na Play Store se destacada o comentário do usuário Henrique: "Comprei por causa do FLAC (muito bom, sem comparação). Único problema é ter que baixar o álbum completo, ainda mais que Flac é mais pesado. Mas um ótimo app". Através deste discurso percebemos que este é um dos argumentos de venda mais fortes do serviço, mas mesmo ressaltando um ponto positivo do TIDAL o usuário sempre pontua desvantagens. É recorrente a identificação de contrapontos em relação ao áudio do serviço, como no tweet do usuário@dutello “É, sem um fone ou sistema de som por alguma entrada que seja boa, não dá pra diferenciar Spotify MP3 320kbps pra Tidal HiFI FLAC”.

O serviço também se apoia na exclusividade de certos conteúdos e na fidelidade que permeia a relação fãs-artista. Dos oitos entrevistados todos afirmaram terem assinado por conta de um artista específico. Quando E3 compartilhou o motivo de sua assinatura, ele disse:

Eu comecei assinando o TIDAL pra escutar o novo CD do Kanye (West), The Life of Pablo, porque ele disse que ia ser exclusivo e que só ia ficar lá, então eu sou muito fã do Kanye então eu pensei 'pô, vale a pena' e eu resolvi ficar por mais um tempo, depois de ter ouvido The Life of Pablo, porque eu sabia que nos mesmo ano a Beyonce ia lançar um novo $\mathrm{CD}$ e que esse $\mathrm{CD}$ ia demorar décadas pra chegar em qualquer outro streaming porque o TIDAL é do Jay Z. Aí eu fiquei pra ver o lançamento do Lemonade e permaneci por causa do CD da Rihanna. Basicamente todos os meus artistas favoritos fazem parte do board do TIDAL e eu fiquei por causa disso. (E3)

Diferente dos outros entrevistados, E7 atribui o tempo que ficou a um serviço extra oferecido: "eu fique sabendo que o TIDAL, quem assinasse poderia comprar um ingresso pro show do Coldplay no Rio ano passado no Maracanã, aí teria direito a comprar na pré venda, então eu fiz a assinatura só pra poder comprar o ingresso na pré venda”. Ele foi o único a usufruir de um dos serviços agregados ao TIDAL.

Ao serem questionados sobre a primeira coisa que vem à cabeça ao pensar em TIDAL, os entrevistados E1, E5 e E6 afirmam que é exclusividade. A popularidade do serviço está diretamente ligada aos artistas que compõem seu acervo, apesar de ser possível identificar nas redes sociais um discurso contrário à proposta do TIDAL. Muitos fãs se sentem pressionados a assinar, o que gera um sentimento de restrição. No Twitter é comum observar comentários como “@hooneybey Baixei essa merda de tidal só por causa da beyoncé do lemonade, mas não gostei não me adaptei prefiro o Spotify”; “@muckyo Só uso TIDAL por causa de Rihanna mesmo, se eu ouço outros artistas é por consequência”. Apesar da conotação dúbia destes tweets, a satisfação por consumir um conteúdo de seu artista preferido tende a se sobrepor. 
Dos quatro ex assinantes entrevistados, três deles confessam ter assinado apenas para usar o período de avalição grátis. Todos já assinavam outro serviço de streaming mas queriam usufruir algum conteúdo exclusivo. E8, por exemplo, teve a assinatura para ouvir o último álbum lançado pela cantora Rihanna, e após o período cancelou a assinatura, pois já tinha conta no Spotify. Da mesma maneira, E6 assinou apenas para ter acesso ao álbum visual da cantora Beyoncé. Todos os entrevistados dizem ter assinado a partir do trial, mas continuaram algum período pelos artistas exclusivos.

Já E6 reforça que a exclusividade pode ser tanto uma força como uma fraqueza do serviço, considerando o contexto do mercado: “é engraçado porque o que eu mais gostei foi ter acesso aos discos que eu não tenho no Spotify e o que eu menos gostei é ter que assinar um serviço diferente do convencional para ter acesso a esses mesmos conteúdos, se tivesse tudo disponibilizado no mesmo lugar eu não precisava assinar dois". Ao restringir o acesso a certos conteúdos, o TIDAL retira da mão do consumidor o poder de escolha, ofendendo a liberdade do público. Segundo um usuário do Twitter “@BITCHBAD Ao invés de valorizar o trabalho do artista, o Tidal só ta estimulando mais pirataria”.

De maneira geral, percebe-se que os assinantes até hoje se sentem satisfeitos com o serviço e não mudariam de plataforma, porém a permanência no TIDAL está condicionada à presença de certos artistas no catálogo, ou seja, a fidelização diz respeito a eles e não ao serviço. E como pontua Barreto (2015) é essencial que a empresa tenha um relacionamento duradouro com o seu cliente baseado na confiança com a marca.

No caso do TIDAL, em relação ao público brasileiro, falta a empresa medir a satisfação de seus consumidores e tomar ações a partir destas informações. Um comentário encontrado na Play Store traduz essa necessidade: "Cara, ta sensacional. Eu tenho conta no Tidal e no Spotify, o Spotify tem maior carinho pelo Brasil, o acervo é bem maior. Mas não dispenso o Tidal, o aplicativo tá sensacional, e a qualidade, só escuto minhas músicas favoritas por ele". Falta ao TIDAL esse carinho por seu público e cuidado na hora de preparar plataforma e conteúdo para recebe-los. A chave para reter clientes está em satisfaze-los. Em geral, um cliente altamente satisfeito permanece fiel por mais tempo, fala bem da empresa e de seus serviços, dá menos atenção a ameaças e propaganda concorrentes e é menos sensível a preço valorizando mais a marca (KOTLER; KELLER, 2006, p. 144). 


\section{CONSIDERAÇÕES FINAIS}

Este artigo teve como objetivo analisar a percepção de valor do TIDAL por parte dos consumidores, de acordo com sua proposta de som de alta qualidade, conteúdo exclusivo e poder aos artistas, considerados seus diferenciais. A fim de alcançar esse objetivo, foram feitas uma análise observacional de tweets e resenhas de usuários na Play Store e entrevistas em profundidade com assinantes e ex-assinantes do serviço. A partir da análise dos comentários, pudemos observar as considerações dos usuários sobre o funcionamento do serviço, suas funcionalidades e seus problemas de desempenho. Enquanto as entrevistas em profundidade proporcionaram uma visão mais subjetiva do TIDAL e de sua proposta.

Como analisado, a alta qualidade de áudio que a plataforma oferece foi pouco percebida pelos usuários, e mesmo quando citada, é sempre junto à necessidade de uso de outros dispositivos que possibilitem essa percepção, como fones de ouvido de maior precisão. Ou seja, apesar da vantagem na qualidade do som, a necessidade de objetos de apoio na experiência torna-se um fator limitador da experiência final e pouco estimulante para a realização de uma assinatura. De qualquer forma, a alta fidelidade do som é vista como algo positivo, sendo uma diferenciação em relação aos outros serviços, mas não valorizada pelos consumidores.

No que diz respeito à exclusividade de conteúdos, as opiniões coletadas atribuem a este fator a sua assinatura. De fato, de todos os atributos, a exclusividade é o principal, sendo que essa exclusividade de certos artistas é percebida como determinante para a permanência dos assinantes, visto que dos quatro assinantes, três declararam não ter intenção de abandonar o uso da plataforma enquanto tiverem acesso aos seus conteúdos exclusivos. Em contraposição, três ex assinantes explicitaram que o motivo pelo qual trocaram de serviço de streaming foi possuírem outros meios de acessar as músicas atualmente restritas ao TIDAL, seja através de outros serviços de streaming, como Spotify ou Youtube, ou da pirataria. Portanto, o conteúdo exclusivo é bom, mas pode ser um pouco diverso. Uma alternativa para potencializar esta característica seria fechar novos contratos de exclusividade com outros artistas, expandindo a biblioteca de conteúdo. Caso contrário, o TIDAL vai se limitar a determinadas comunidades de fãs, como acontece atualmente como os da Beyoncé, por exemplo.

Desta forma é possível inferir que, mesmo com som de alta fidelidade e artistas exclusivos constituírem importantes diferenciais, é preciso investir no desenvolvimento de novas funcionalidades e criação de atrativos que expandam a penetração do TIDAL no mercado. 
Outro ponto sensível às críticas foi a recomendação de conteúdos, tida como curadoria, por parte do TIDAL. A falha demonstrada na sugestão de músicas e/ou playlists semelhantes ao gosto de cada usuário revela uma falta de cuidado com o serviço oferecido, mesmo este sendo uma das propostas de diferenciação da plataforma. O TIDAL promete oferecer aos seus assinantes conteúdo diferenciado e playlists com curadoria dos próprios artistas, mas não entrega tudo, ou entrega mal, ao sugerir sempre o mesmo tipo de artista ao usuário. Assim, uma das grandes vantagens do streaming se perde, ao não dar conteúdo personalizado de acordo com as preferências do usuário. Diferente do que ocorre com o Spotify, seu principal concorrente, que é conhecido pelas inúmeras playlists individualizadas e seus algoritmos de recomendação de acordo com o histórico e classificação dos usuários, neste ponto o TIDAL ainda possui melhorias a serem feitas, a começar por uma interface mais amigável, que facilite a criação e compartilhamento de playlists. Este fator está muito ligado ao lado social da plataforma que, se bem explorado, poderia contribuir para o crescimento dela. Falta ao TIDAL explorar os fandoms existentes dentro do serviço, oferecendo interatividade entre os usuários, seja na visualização do que cada um está escutando no momento ou criação de playlists colaborativas, qualquer coisa que engaje seus usuários.

Apesar das críticas, foi possível identificar que os assinantes entrevistados demonstram uma inclinação em continuar usando o serviço, apesar dos problemas e limitações relatados, pois o que eles mais valorizam são os artistas que compõe a biblioteca do TIDAL, principalmente aqueles que são exclusivos. Também foi observado que, talvez por influência de Jay-Z, dono da plataforma, os artistas em destaque seguem a mesma linha de trabalho, pertencendo a estilos musicais semelhantes. Neste momento, o TIDAL assume um caráter de nicho, onde o ponto forte de sua biblioteca são gêneros como Hip-hop, $R \& B$ e Rap, que compõem a maior fatia de seu acervo musical. Se a proposta inicial fosse se estabelecer como um serviço especializado em tais gêneros, o TIDAL provavelmente seria mais bem-sucedido, mas deveria se posicionar corretamente e comunicar isso ao público.

Sendo assim, compreende-se que, apesar dos esforços do TIDAL em divulgar seu serviço e ampliar sua base de assinantes, os argumentos escolhidos pouco ajudam a alcançar tal objetivo. Som de alta definição e conteúdo exclusivo, sozinhos, não bastam para bater de frente com o Spotify, líder no mercado brasileiro. A questão do pagamento de royalties tampouco contribui como motivação para os usuários, como visto nas entrevistas, e sequer aparece nas resenhas publicadas na loja de apps do Google. O TIDAL elegeu como bandeira um tema totalmente alheio ao seu público-alvo e paga por isso. 
Quanto ao esforço dedicado em trabalhar sua marca, o TIDAL também deixa a desejar. A plataforma não inspira simpatia, nem envolve os usuários com sua comunicação. Foi possível observar em suas páginas no Twitter e na Play Store, que existe um distanciamento entre marca e consumidores. A comunicação é escassa, e, quando feita, é sempre com proposito de remediar uma situação. A ideia de lovemark passa longe, apesar de ser uma empresa jovem e com alto potencial de engajamento, o TIDAL pouco trabalha sua relação com os usuários no Brasil. Um único entrevistado relatou usufruir de vantagens oferecidas pelo TIDAL, ao ter direito a uma pré-venda de ingressos. Uma solução seria promover mais vantagens como o acesso a prévenda de ingressos, como citado anteriormente, meet and great com seus artistas, quando esses viessem ao país, acesso a mais transmissões ao vivo de shows ao redor do mundo, edições de seu festival, o TIDAL X, fora dos Estados Unidos e suporte a novos artistas de outros países. Ou seja, criar alternativas que transformassem o TIDAL em mais do que uma plataforma de streaming, em uma comunidade de fãs, um clube de vantagens para os apaixonados por música ao redor do globo. Já vemos algumas dessas ações em outros mercados mundo afora, mas sempre pontuais. Sua estratégia se baseia na exclusividade dos artistas, mas peca em ignorar a construção de um relacionamento com os usuários a longo prazo.

Desta maneira, infere-se que, apesar de se demonstrarem satisfeitos, os usuários encontram-se acomodados com o uso da plataforma, por estarem reféns de sua exclusividade e da pouca oferta de funcionalidades, seus diferenciais não são suficientes e a exclusividade oferecida em muitos momentos soa como coação.

Por fim, cabe destacar que o presente trabalho possui limitações no que diz respeito ao seu método e à amostra, não podendo ser generalizado para todo o ambiente do TIDAL, nem para demais serviços de streaming. Há uma necessidade de uma ampliação da pesquisa, o que se sugere para futuras pesquisas. No mais, por se tratar de um tema amplo e em constante mudança, verifica-se a necessidade de estudos constantes a fim de reavaliar as transformações ocorridas neste mercado e sobre a satisfação dos seus consumidores, tão importante para os relacionamentos de longo prazo.

\section{REFERÊNCIAS}

ALBRIGHT, Dann. The evolution of music consumption: how we got here. MUO. 2015. Disponível em: http://www.makeuseof.com/tag/the-evolution-of-music-consumption-howwe-got-here/ - Acesso em: 20 ago. 2017. 
ALVES, Paulo. Como funciona o eMule. TechTudo. 22 nov. 2015. Disponível em: http://www.techtudo.com.br/dicas-e-tutoriais/noticia/2015/11/como-funciona-o-emule.html Acesso em: 24 out. 2017.

BANDEIRA, Messias G. A economia da música online: propriedade e compartilhamento da informação na sociedade contemporânea. V Encontro Latino de Economia Política da Informação, Comunicação e Cultura. EDUFBA. Anais.. Salvador, 2005.

BARRETO, Iná. Resultados de Marketing de Relacionamento: proposição de modelo por meio de mapeamento cognitivo. Tese (Doutorado em Administração). FEA/USP. São Paulo, 2015 .

BENCHER, Yochai. The Wealth of Networks: How Social Production Transforms Markets and Freedom. New Haven: Yale University Press, 2006. 528 p.

CARVALHO, Marcelo. A trajetória da internet no Brasil: do surgimento das redes de computadores à instituição dos mecanismos de governança. Dissertação (Mestrado em Engenharia). COPPE/UFRJ. Rio de Janeiro, 2006.

CARVALHO, João Paulo. Consumo de música por streaming volta a crescer e chega a 112 milhões de assinantes. Estadão. 23 maio. 2017. Disponível em:

http://cultura.estadao.com.br/noticias/musica,consumo-de-musica-por-streaming-volta-acrescer-e-chega-a-112-milhoes-de-assinantes,70001808591 - Acesso em 15 nov. 2017.

CASTRO, S. G. Gisela. Para pensar o consumo da música digital. Revista FAMECOS, Porto Alegre, n. 28, p 30-36, dezembro. 2005.

CASTRO, S. G. Gisela. Pirataria na Música Digital: Internet, direito autoral e as novas práticas de consumo. UNIrevista. Rio Grande do Sul, vol. 1, n. 3, julho. 2006.

COM STREAMING, indústria musical registra crescimento de 5,9 em 2016. UOL. 25 abr. 2017. Disponível em: https://musica.uol.com.br/noticias/afp/2017/04/25/com-streamingindustria-musical-registra-crescimento-de-de-59-em-2016.htm - Acesso em: 26 abr. 2017.

COOK, James. Jay Z's music streaming servisse Tidal has been accused of not paying its bills. Business Insider. 13 set. 2016. Disponível em http://www.businessinsider.com/jay-zmusic-streaming-service-tidal-accused-of-not-paying-its-bills-2016-9 - Acesso em: 15 out. 2017. 
DE MARCHI, Leonardo; ALBORNOZ, Luis Alfonso; HERSCHMANN, Micael. Novos negócios fonográficos no Brasil e a intermediação do mercado digital de música. Revista FAMECOS. Porto Alegre, v. 18, n.1, p. 279-291, jan/abr. 2011.

FRANCISCO, Pedro Augusto Pereira; VALENTE, Mariana Giorgetti. (Org). Da rádio ao streaming: ECAD, direito autoral e a música no Brasil. Rio de Janeiro: Beco do Azougue, 2016.

FERRARI, Bruno. A popularização do streaming pode mudar a forma como apreciamos música. Revista Época. Ideias. 1 mar. 2015. Disponível em:

http://epoca.globo.com/ideias/noticia/2015/03/bpopularizacao-do-streamingb-podemudarforma-como-apreciamos-musica.html - Acesso em: 10 set. 2017.

GARRET, Filipe. FLAC ou AAC? Saiba qual formato de áudio é melhor. TechTudo. 21 maio. 2017. Disponível em: https://www.techtudo.com.br/noticias/2017/05/flac-ou-aac-saibaqual-formato-de-audio-e-melhor.ghtml - Acesso em: 8 out. 2017.

GLOBAL Music Report. IFPI. 2016. Disponível em: http://www.ifpi.org/news/IFPIGLOBAL-MUSIC-REPORT-2016 - Acesso em: 13 ago. 2017.

GREENBURG, Zack O’Malley. Has Jay Z's Tidal been inflating subscriber numbers? Forbes. 20 jan. 2017. Disponível em: https://www.forbes.com/sites/zackomalleygreenburg/2017/01/20/has-jay-zs-tidal-beeninflating-subscriber-numbers/\#4942033a24dd Acesso em: 10 out. 2017.

HAVENS, Lyndsey. Tidal X concert returns for second year with Beyoncé, Nicki Minaj, Alicia Keys \& more. Billboard. 16 out. 2016. Disponível em: http://www.billboard.com/articles/columns/pop/7542039/tidal-X-concert-second-year-recapbeyonce-nicki-minaj-alicia-keys Acesso em: 05 out. 2017.

HERSCHMANN, Micael. Indústria da música em transição. Estação das Letras, São Paulo, 2010.

JORDÃO, Fabio. Spotify vs todos: quem se sai melhor no mercado de streaming musical? TecMundo. 08 maio 2016. Disponível em: https://www.tecmundo.com.br/spotify/104539spotify-vs-rapa-sai-melhor-mercado-streaming-musical.htm - Acesso em: 13 out. 2017. 
KANYE West deixa o Tidal, de Jay-Z, em briga milionária, diz site. G1. 03 jul. 2017. Disponível em: https://g1.globo.com/musica/noticia/kanye-west-deixa-o-tidal-de-jay-z-embriga-milionaria-diz-site.ghtml - Aceso em: 15 out. 2017.

KISCHINHEVSKY, Marcelo; VICENTE; Eduardo; DE MARCHI, Leonardo. Em busca da música infinita: os serviços de streaming e os conflitos de interesse no mercado de conteúdos digitais. Fronteiras. Rio Grande do Sul. Vol. 17, n. 3, set/dez. 2015.

KISCHINHEVSKY, Marcelo; HERSCHMANN, Micael. Tendências da indústria da música no início do século XXI. In: Janotti Jr, Jeder Silveira; Lima, Tatiana Rodrigues; Pires, Victor de Almeida Nobre (orgs.). Dez anos a mil: mídia e música popular massiva em tempos de internet. Porto Alegre: Simplíssimo Editora. part. 1, cap.2 ,p. 23-34, 2011.

KLEINA, Nilton. Por onde anda o Kazaa? TecMundo. 05 out. 2011. Disponível em: https://www.tecmundo.com.br/p2p/14033-por-onde-anda-o-kazaa-.htm Acesso em: 24 set. 2017.

KOTLER, Philip; KELLER, Kevin L. Administração de Marketing. 12a edição. São Paulo: Pearson, 2006.

LIMA, Clóvis Ricardo Montenegro de; SANTINI, Rose Marie. Música e cibercultura.

Revista FAMECOS. Porto Alegre, n 40, p 51-56, dezembro. 2009.

MALHOTRA, Naresh. Pesquisa de Marketing: Uma orientação aplicada. $3^{\mathrm{a}}$ ed. Bookman. Porto Alegre, 2001.

MARTINS, João P. Capelli; SLONGO, Luiz Antonio. O Mercado de Música Digital: um estudo sobre o comportamento do consumidor brasileiro. Revista Brasileira de Gestão de Negócios. São Paulo, v. 16, n. 53, p. 638-657, out/dez. 2014.

McALONE, Nathan. Jay Z's Tidal music streaming service more than doubled its losses last year. Business Insider. 13 set. 2016. Disponível em: http://www.businessinsider.com/tidallosses-accelerated-in-2015-2016-9 Acesso em: 15 out. 2017.

QUAL SERVIÇO de streaming musical paga melhor os artistas? Rolling Stone Brasil. 12 ago. 2017. Disponível em: http://rollingstone.uol.com.br/blog/descubra-qual-e-o-servico-destreaming-musical-que-melhor-paga-os-artistas/ Acesso em: 05 out. 2017. 
ROCHA, Pedro. TIDAL, o serviço de música do Jay-Z, chega oficialmente ao Brasil. Papel Pop. 29 set. 2015. Disponível em: http://www.papelpop.com/2015/09/tidal-o-servico-demusica-do-jay-z-chega-oficialmente-ao-brasil/ Acesso em: 10 set. 2017.

RIBEIRO, Carlos. Do analógico para o digital: os novos modelos de partilha e venda de música online - plataformas de streaming. Dissertação (Mestrado em Psicologia). ESECS/IPP. Porto Alegre. 2016.

SANTINI, Rose Marie. Admirável Chip Novo: A música na era da internet. E-Papers, Rio de Janeiro, 2006.

SASSARD, Sophie. Deezer: The French music streaming service taking on Spotify, Apple and Amazon. Independent. 20 set. 2017. Disponível em:

http://www.independent.co.uk/news/business/analysis-and-features/deezer-music-streamingspotify-amazon-apple-subscritpiton-hans-holger-albrecht-len-blavatnik-a7940896.html

Acesso em: 14 out. 2017.

SHAW, Lucas. Taylor Swift retorna ao Spotify após boicote de quase três anos. UOL. 09 jun. 2017. Disponível em: https://economia.uol.com.br/noticias/bloomberg/2017/06/09/taylorswift-retorna-ao-spotify-apos-boicote-de-quase-tres-anos.htm - Acesso em: 6 out. 2017.

SMOUT, Alistair. Gravadoras atingem em 2016 mais rápido crescimento em 20 anos com ajuda de serviços de música online. REUTERS. 25 abr. 2017. Disponível em:

http://br.reuters.com/article/internetNews/idBRKBN17R27P-OBRIN - Acesso em: 13 ago. 2017.

SILVA JR, Flávio Marcílio Maia e. Na onda do streaming: Plataformas Digitais Sonoras no Mercado Musical Brasileiro. Intercom. Anais...Caruaru - PE. 2016.

STREAMING cresce 52,4\% no Brasil!. ABRAMUS. 25 maio 2017. Disponível em: https://www.abramus.org.br/noticias/13397/streaming-cresce-524-no-brasil// Acesso em: 15 nov. 2017.

TAPIA, Andrea. 10 exitosos artistas que se rebelaram contra Spotify. T13. Disponível em: http://www.t13.cl/noticia/tendencias/espectaculos/10-exitosos-artistas-que-se-rebelaroncontra-spotify - Acesso em: 05 out. 2017.

TIDAL paga aos artistas quase o dobro em royalties por música executada do que o Spotify. O Globo. 04 jun. 2016a. Disponível em: https://oglobo.globo.com/cultura/musica/tidal-paga- 
aos-artistas-quase-dobro-em-royalties-por-musica-executada-do-que-spotify-16052089 Acesso em: 05 out. 2017.

TIDAL 2016: um ano de exclusividades. Exame. 27 dez. 2016b. Disponível em: http://exame.abril.com.br/negocios/releases/tidal-2016-um-ano-de-exclusividades/ Acesso em: 7 set. 2017.

TIDAL. Stream of Consciousness. 2018. Disponível em: http://tidal.com/soc/ Acesso em: 05 mar. 2018.

WACHOWICZ, Marcos; VIRTUOSO, Bibiana Biscaia. A gestão coletiva dos direitos autorais e o streaming. P2P \& INOVAÇÃO, Rio de Janeiro, v. 4 n. 1 p.4-17, Set./ Fev. 2018. Disponível em: http://revista.ibict.br/p2p/article/view/3981/3312 Acesso em: 05 mar. 2018.

YIN, Robert K. Estudo de Caso: Planejamento e Métodos. $2^{\text {a }}$ ed, Bookman. Porto Alegre, 2001. 